\title{
The Influence of Heat on Appetite-Regulating Adipokines
}

\author{
Mark L McGlynn ${ }^{1}$, Robert J Shute ${ }^{2}$ and Dustin R Slivka ${ }^{1 *}$ \\ ${ }^{1}$ University of Nebraska at Omaha, School of Health and Kinesiology, USA \\ ${ }^{2}$ University of Virginia School of Medicine, Cardiovascular Research Center, USA
}

Submission: March 04, 2020; Published: March 12, 2020

*Corresponding author: Dustin R. Slivka, PhD, CSCS, FACSM, School of Health and Kinesiology, University of Nebraska at Omaha, USA

\begin{abstract}
Leptin has been established as an energy-controlling hormone because of its role in activating the JAK-STAT3 pathway. Exercising in the heat (1-hour of cycling @60\% V02max in $33^{\circ} \mathrm{C}$ ) has induced reductions in leptin. However, in order to better understand the influence of environmental temperature, independent of exercise, a fasted resting investigation is needed. This investigation explored the impact of environmental temperature $\left(33 \mathrm{vs.} 20^{\circ} \mathrm{C}\right)$ on adipose-derived appetite-regulating hormones (leptin and adiponectin) and energy expenditure. Ten college-aged males $(27 \pm 5 \mathrm{y}, 86 \pm 13 \mathrm{~kg}$, and $183 \pm 4 \mathrm{~cm})$ completed two randomized, resting trials in the Heat $\left(\mathrm{HT}, 33^{\circ} \mathrm{C}\right)$ and in Room Temperature (RT, $\left.20^{\circ} \mathrm{C}\right)$. Blood draws were taken pre-intervention and $3 \mathrm{~h}$ post-intervention for analysis of leptin and adiponectin. Oxygen consumption was measured at $1-, 2$-, and 3-h timepoints. HT trial temperatures were greater than RT for core $\left(37.17 \pm 0.08\right.$ vs. $\left.36.89 \pm 0.08^{\circ} \mathrm{C}, \mathrm{p}=0.002\right)$ and skin $(37.59 \pm 0.10$ vs. $\left.32.65 \pm 0.48^{\circ} \mathrm{C} ; \mathrm{p}<0.001\right)$. Oxygen consumption was higher in HT than RT during the $2^{\text {nd }}(4.37 \pm 0.14 \mathrm{vs.} 4.13 \pm 0.15 \mathrm{ml} / \mathrm{kg} / \mathrm{min}, \mathrm{p}=0.037)$ and $3^{\text {rd }}$ ( $4.95 \pm 0.26$ vs. $4.28 \pm 0.19 \mathrm{ml} / \mathrm{kg} / \mathrm{min}, \mathrm{p}=0.002$ ) hours. Fasting leptin concentrations in RT decreased to a greater extent than in HT (mean $\Delta \pm S E M$; $-2.05 \pm 0.83$ vs. $-0.89 \pm 0.74 \mathrm{ng} / \mathrm{ml} ; \mathrm{p}=0.032)$; however, after adjustment for plasma volume shifts $(-7.5 \pm 4.2 \%)$ the interaction disappeared (mean $\Delta \pm$ SEM; $-1.79 \pm 1.72$ vs. $-0.89 \pm 0.74 \mathrm{ng} / \mathrm{ml} ; \mathrm{p}=0.068$ ). Heat stress increased oxygen kinetics and attenuated the normal reduction in leptin over time, effectively slowing the rise in hunger (maintaining satiety) within a fasted state. These data may have implications for appetite control, weight management, and nutritional interventions during heat exposure.
\end{abstract}

Keywords: adipokines; leptin; adiponectin; heat; obesity; satiety; intermittent fasting

Abbrevations: RT: Room Temperature; HT: Heat; SEM: Standard Error of the Mean; PVA: Plasma Volume Adjustments; HPA: hypothalamicPituitary-Adrenal; AMPK: AMP-Activated Protein Kinase; RER: Respiratory Exchange Ratio

\section{Introduction}

Obesity continues to spread across the globe despite ample research warning of its connection with many chronic diseases; such as; cardiovascular disease, diabetes mellitus, and some neurodegenerative disorders [1]. The Obesity gene and the hormone it encodes, leptin, was discovered in 1994 by Zhang and colleagues [2] with great potential to combat obesity. Leptin and adiponectin are appetite-regulating hormones released into circulation from adipose tissue (adipokines) with a direct influence over the hypothalamic-pituitary-adrenal (HPA) axis [3] and thus, have some influence over the human appetite. Logically, a simple solution to weight loss is to limit energy intake (restrict caloric intake) and increase energy expenditure (e.g., exercise); however, the influence of the human appetite consistently defeats this logic. Therefore, research into the physiological role of appetite regulating hormones may be a potential therapeutic pathway by blunting the overwhelming power of hunger and the need for satiety.

Leptin has been established as an important energycontrolling hormone because of its role in activating the JAKSTAT3 energy-regulating pathway. Circulating leptin crosses the blood brain barrier and influences the HPA axis to inhibit hunger and stimulate satiety [4]. Adiponectin seems to follow the same route as demonstrated by its presence within the cerebral spinal fluid and its action on the hypothalamus to stimulate the AMPactivated protein kinase (AMPK) pathway [5]. Although these appetite regulating hormones have similar sites of influence, evidence suggests they work in opposition to one another. More specifically, adiponectin reverses the leptin-induced suppression 
of AMPK, which is an initiator of glucose and fatty acid oxidation when cellular energy is low [5]. More importantly, the translation of these non-human models conducted within temperaturecontrolled environments requires confirmation in humans.

Environmental temperature has its own prominent role governing appetite regulation and thus, energy expenditure. A decrease in serum leptin may represent an adaptive mechanism intended to increase food intake to maintain fat deposits during the winter months. The hypothalamus can be directly influenced by an increase in temperature resulting in the reduction of food intake in mice,[6] presumably from greater concentrations of leptin within circulation, which could be via an upregulation or decelerated metabolic breakdown. In theory, these non-human models [5-7] should hold true; however, major differences within the mechanisms of most mammalian thermoregulation suggest the need for further human testing.

Previous murine research has demonstrated consistent decreases in leptin while in a fasted state[8]. Human investigations have provided evidence explaining the influence of exercise and heat (1-hour of cycling at $60 \% \mathrm{VO}_{2}$ max at 33 ${ }^{\circ} \mathrm{C}$ ), demonstrating increases in adiponectin (greater hunger) and decreases in leptin (satiety) concentrations [9]. However, in order to elucidate the influence of heat, independent of exercise, a fasted, resting investigation is necessary. Therefore, the purpose of this investigation was to determine the impact of heat (33 vs. 20 ${ }^{\circ} \mathrm{C}$ ) on appetite-regulating hormones and how this can manifest in energy expenditure, independent of the exercise effect. More specifically, we hypothesize that fasting in room temperature (RT) will allow for a decrease in leptin and an increase in adiponectin. Alternatively, fasting within the heat (HT) will increase energy expenditure and thus, blunt the change in leptin and amplify the increase in adiponectin as compared to the RT condition.

\section{Methods}

These methods have been previously published with some modifications. Additionally, the results of this investigation are a subset of data collected under the same circumstances [10] that reported skeletal muscle gene expression. In order to better explain the results of this investigation, the raw data has been re-analyzed with an $\mathrm{n}$ of 10 subjects. Approval was granted from the Institutional Review Board of the University of Nebraska at Omaha.

\section{Subjects}

All participants ( $\mathrm{n}=10$ males; $27 \pm 5 \mathrm{y}, 86 \pm 13 \mathrm{~kg}$, and 183 $\pm 4 \mathrm{~cm}$ ) were informed of the procedures and associated risks before completing the consent process. Participants arrived at the laboratory on two occasions separated by at least 2 days, at the same time of day (between 7-10am), having fasted overnight and refrained from exercise (above their normal routine) for the previous $48 \mathrm{~h}$. The two experimental trials were completed in a repeated-measures, randomized order and consisted of 3 $\mathrm{h}$ of sitting in an environmentally controlled chamber (Darwin Chambers Company, St. Louis, Mo., USA) at two temperatures, heated $\left(\mathrm{HT}=33^{\circ} \mathrm{C}\right)$ and room temperature $\left(\mathrm{RT}=20^{\circ} \mathrm{C}\right)$ at $60 \%$ relative humidity. Participants were natives of the area (average area temperature at the time of data collection was $13.8^{\circ} \mathrm{C}$ or 56.8 ${ }^{\circ} \mathrm{F}$ ) and wore standardized shorts and t-shirts during the trials and provided water ad libitum.

\section{Trial Data}

Continuous core (rectal suppository; Jonah Core Body Capsule) and skin (vest; $\mathrm{EQO}_{2}$ Lifemonitor) temperatures were collected at $15 \mathrm{~s}$ intervals and integrated via Hidalgo Limited Software (Cambridge, UK). Expired gases were collected at baseline and each hour for 5-min intervals to analyze oxygen utilization via a metabolic cart (ParvoMedics TrueOne Metabolic System, Sandy, Utah). The last 3 min of $\mathrm{O}_{2}$ and $\mathrm{CO}_{2}$ were averaged in order to estimate fuel usage during the trail via the respiratory exchange ratio (RER; $\mathrm{VCO}_{2} / \mathrm{VO}_{2}$ ). Blood draws were taken pre- and post-trial in order to measure blood variables.

\section{Blood Variables}

As previously described by Laursen and colleagues [9], approximately $6 \mathrm{ml}$ of blood was taken from the antecubital vein of the arm and drawn into EDTA vacutainer tubes. Whole blood was immediately tested for hemoglobin and hematocrit values in order to estimate each participant's plasma volume shift over time in order to calculate plasma volume adjusted (PVA) hormone concentrations[11]. The whole blood was separated into plasma via centrifuge at 10,000 x g for $15 \mathrm{~min}$ and stored at $-80^{\circ} \mathrm{C}$. Quantification of circulating plasma adipokines (leptin and adiponectin) were completed according to the manufacturer's (Life Technologies Corporation, Frederick, MD) instructions using separate prepackaged ELISA kits. Plasma samples were diluted (leptin 1:100 and 1:2000) and the mean of duplicate samples was used for statistical analysis.

\section{Statistical Analyses}

Differences in the resting trial data $(2 \times 3)$ and blood variables $(2 \times 2)$ were analyzed with a repeated measures ANOVA (trial $x$ time). If significance was indicated with the initial analysis, a Fisher's LSD post-hoc test was used to identify where significant differences occurred. A probability of type I error of less than $5 \%$ was considered significant $(p<0.05)$. Statistical analysis was completed using SPSS (v.26, IBM, N.Y., USA). All data are presented in mean \pm standard error of the mean (SEM), unless noted otherwise.

\section{Results}

\section{Trial Data}

Baseline (pre-intervention) core $\left(\mathrm{HT}=37.2 \pm 0.4{ }^{\circ} \mathrm{C}\right.$; RT $=$ $\left.37.0 \pm 0.3{ }^{\circ} \mathrm{C}\right)$ and skin $\left(\mathrm{HT}=34.7 \pm 0.2{ }^{\circ} \mathrm{C}\right.$; RT $\left.=34.6 \pm 0.3{ }^{\circ} \mathrm{C}\right)$ 


\section{Current Research in Diabetes \& Obesity Journal}

temperatures were similar between each condition. After three hours in the HT, core temperatures increased $(180 \mathrm{~min}=37.3$ $\pm 0.2 ; p<0.05)$ and skin temperatures increased (37.6 \pm 0.3$)$ from baseline $(p<0.05)$. RT values decreased (core $=36.8 \pm 0.4$ and skin $=32.6 \pm 1.6 ; p<0.05$ ) from baseline, see Figure 1 for further temperature comparisons. Oxygen consumption in the heat increased over time (hours 2 and $3>$ hour 1 ) and was higher than the RT condition at hour 2 and 3, see Table 1. Respiratory exchange ratio (RER) went unchanged at the $2^{\text {nd }}$ and $3^{\text {rd }}$ hours $(p>0.05)$ and was not different among temperature conditions $(p>0.05)$

Table 1: Energy expenditure.

\begin{tabular}{|c|c|c|c|}
\hline & $\mathbf{1}^{\text {st }}$ hour & $\mathbf{2}^{\text {nd }}$ hour & $\mathbf{3}^{\text {rd }}$ hour \\
\hline $\mathbf{V O}_{2}$ ( $\left.\mathbf{m l} / \mathbf{k g} / \mathbf{m i n}\right)$ & & & \\
\hline $\mathrm{RT}$ & $3.88 \pm 0.11$ & $4.13 \pm 0.15$ & $4.28 \pm 0.19$ \\
\hline $\mathrm{HT}$ & $3.91 \pm 0.10$ & $4.37 \pm 0.14^{*} \dagger$ & $4.95 \pm 0.26^{*} \dagger \neq$ \\
\hline RER $\left(\mathbf{V C O}_{2} / \mathbf{V O}_{2}\right)$ & & & \\
\hline $\mathrm{RT}$ & $0.83 \pm 0.02$ & $0.84 \pm 0.02$ & $0.85 \pm 0.03$ \\
\hline $\mathrm{HT}$ & $0.79 \pm 0.02$ & $0.82 \pm 0.02$ & $0.81 \pm 0.01$ \\
\hline
\end{tabular}

Note: * $>\mathrm{RT}, \dagger>1^{\text {st }}$ hour, $\ddagger>2^{\text {nd }}$ hour; RT is room temperature, $\mathrm{HT}$ is heat, data is averaged over 3 min intervals at each hour; $p<0.05$; mean \pm SEM.

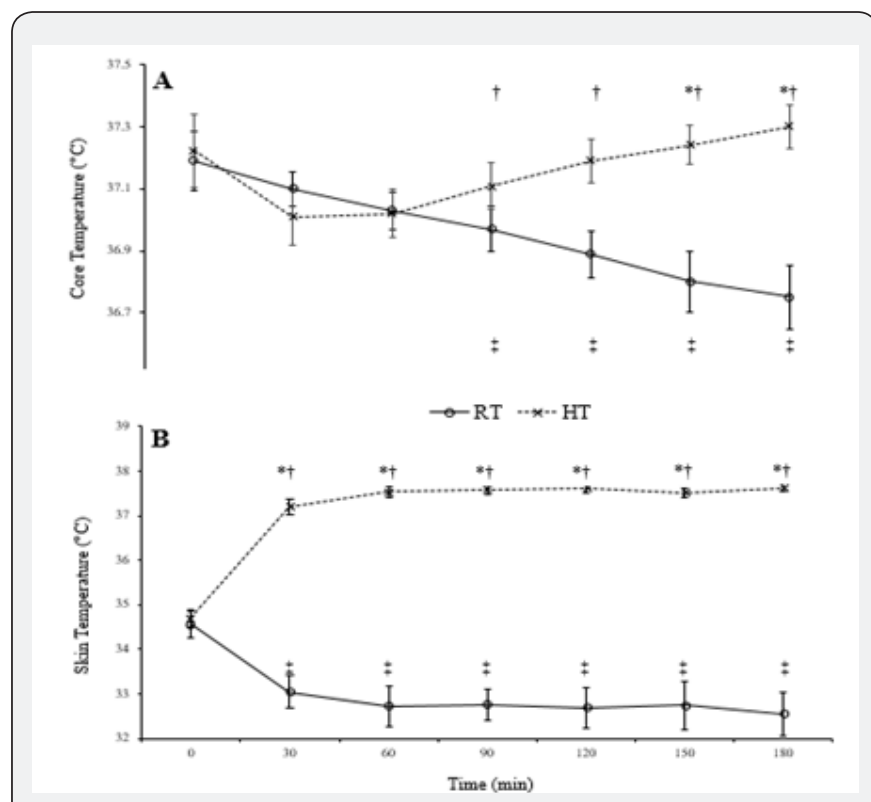

Figure 1: Core temperatures $(A)$ and skin temperatures $(B)$ during the resting trials. Note: * $>0, \dagger>\mathrm{RT}, \ddagger<0 \mathrm{~min} ; p<0.05$; data are mean \pm SEM.

\section{Blood Variables}

Prior to applying corrections for plasma volume shifts, leptin decreased from baseline in the HT condition only (interaction effect; $p=0.032$ and a post-hoc statistic of $p=0.036$ ). However, after adjusting for plasma volume shifts, effectively diluting the plasma concentrations (on average 7.5\%), this leptin reduction was attenuated (leptin $=-2.05 \pm 0.83 \mathrm{ng} / \mathrm{ml}$ vs. PVA leptin $=-1.79$ $\pm 1.72 \mathrm{ng} / \mathrm{ml}$ ), and the ANOVA statistical interaction disappeared ( $p=0.068)$. Plasma leptin concentrations decreased over time (main effect), independent of the condition, for both uncorrected $(p<0.001)$ and PVA concentrations $(p<0.001)$, see Figure 2 . Plasma adiponectin concentrations did not change with time or temperature, regardless of PVA, see Figure 3. Hemoglobin and hematocrit increased (main effect) during the 3-h resting trial ( $p$ $=0.006$ and $p=0.017$, respectively). Hemoglobin and hematocrit were used to calculate and apply PVA to the post-trial leptin and adiponectin concentrations.
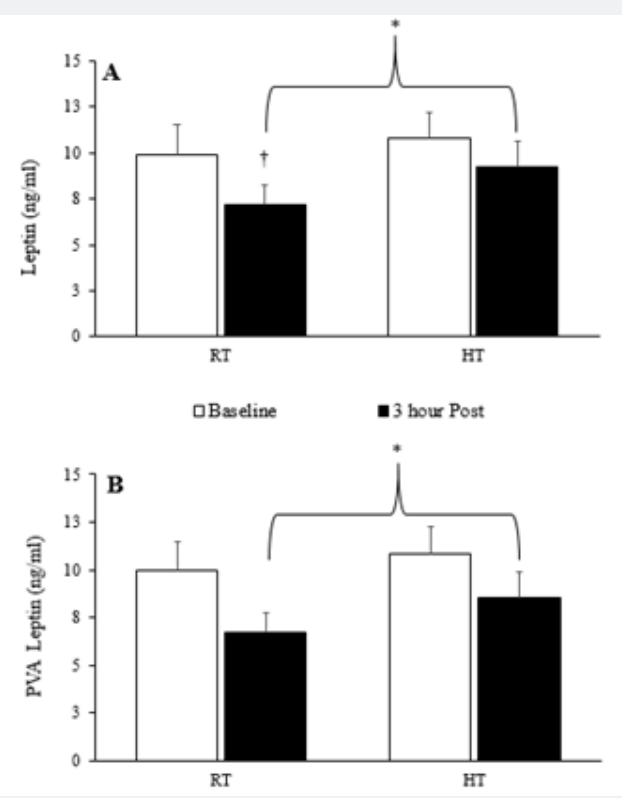

Figure 2: (A) uncorrected, fasted plasma leptin concentrations; (B) fasted plasma volume adjusted (PVA) leptin concentrations; * < Baseline (main effect for time); $\dagger<$ Baseline (interaction for condition); $p=0.036$; data are mean \pm SEM.
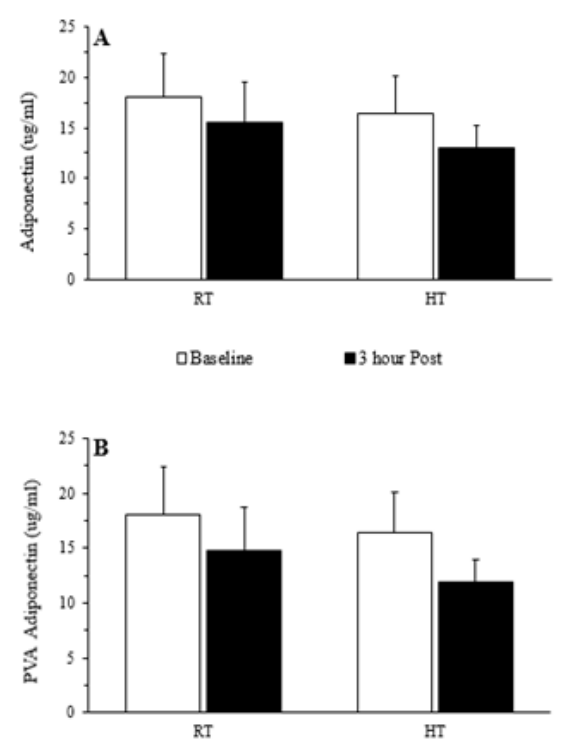

Figure 3: (A) uncorrected fasted plasma adiponectin concentrations; (B) fasted plasma volume adjusted (PVA) adiponectin concentrations; $p>0.05$; data are mean \pm SEM. 


\section{Current Research in Diabetes \& Obesity Journal}

\section{Discussion}

The primary objective of this investigation was to determine the impact of heat on plasma concentrations of appetite-regulating hormones in a fasted state. Plasma leptin concentrations decreased over time while in a fasted state. Therefore, these data suggest fasting in the heat may enhance leptin's primary role of initiating (or in this case maintaining) satiety, reducing the sensation of hunger, in order to maintain fat cell size. After correction for plasma volume loss, this drop in leptin within the HT condition was attenuated; however, the trend is clear that heat slowed leptin kinetics. Independent of the PVA data, there is support for heat's influence to attenuate the normal fall of leptin concentrations. An increase in oxygen consumption over the 3 $\mathrm{h}$ trial suggests the HT condition induced greater ventilation, presumably via increased peripheral blood flow, to dissipate the rise in skin temperatures. Furthermore, the trial data suggests a trend, that did not reach significance $(p=0.066)$, toward greater fat oxidation. This metabolic shift, within a fasted state, suggests the body is transitioning from a state of hunger to a state of satiety, or in this case is maintaining, a state of satiety, which is the primary goal of leptin[4]. Although, this acute investigation (3 hours) did not identify shifts in energy utilization (RER), if data collection was continued (i.e., > 3 hours), this shift may have been detected. After PVA, heat's influence over leptin was attenuated; however, much like the RER data, if data collection was continued beyond $3 \mathrm{~h}$, a statistical difference may have been detected.

The other clear finding of this investigation is the confirmation of previous non-human models,[5-7] demonstrating reductions in leptin with prolonged fasting. This supports previous research suggesting one of the central actions of leptin is to signal the HPA axis of acute changes in energy intake[12]. More recently, intermittent fasting for a period of ten-hours has shown promise to reduce cardiovascular risk factors in metabolic syndrome patients[13]. Interestingly, these patients improved their cardiovascular risk factors (weight, blood pressure and lipid profile) by only adjusting the timing of their eating habits, not reducing their caloric intake. This latest finding highlights the possible therapeutic roles of controlling energy expenditure (increased $\mathrm{VO}_{2}$ without exercise) via the complex regulation of appetite regulating adipokines.

Reductions in plasma volume $(-7.5 \%)$ can cause a hemoconcentration effect that distorts the concentration measurement (i.e., $\mathrm{ng} / \mu \mathrm{g} / \mathrm{dl}$ or $\mathrm{ng} / \mu \mathrm{g} / \mathrm{dl}$ ) thus, the actual amount of "protein" within the blood may not have changed. Therefore, it is necessary to correct for plasma volume adjustments (PVA) by diluting the post-trial blood variables (i.e., correcting for $7.5 \%$ plasma loss), possibly confirmed due to sweating in the HT. After correction for plasma volume loss, the drop in leptin was attenuated (leptin $=-2.05 \pm 0.83 \mathrm{ng} / \mathrm{ml}$ vs. PVA leptin $=-1.79$ $\pm 1.72 \mathrm{ng} / \mathrm{ml}$ ) and no statistically significant interaction was detected, although the trend remained $(p=0.068)$.

Revisiting the hypotheses, our results demonstrated heat exposure initiated an increase in oxygen kinetics to account for an increased need to dissipate heat and thus, presumably a shift in metabolic resources, initiating a blunted drop in leptin; however, after plasma volume shifts, this data did not completely back the hypothesis. Based on previous findings[9] and the role of adiponectin within the AMPK pathway [5], we predicted the rise in adiponectin, independent of the temperature condition. This hypothesis was not supported by the plasma adiponectin concentrations in the current study. These data support previous research suggesting adiponectin only accumulates in the blood after significant weight loss ( $>10 \%$ initial body weight) or due to extreme changes (e.g., surgical interventions) [14].

The amount of fat cells and the status of fat cells are highly dependent upon body composition and have been strongly correlated with amount of fat mass [12]. Unfortunately, body composition was not assessed in the current study; however, because each subject completed both conditions, this should not have had a large impact on the results. More specific techniques (free vs. bound; high molecular weight vs low molecular weight) may provide a better representation of the appetite-regulating hormone's action [15].

Moving forward, further investigations need an extended fasting period for several reasons. (i) The core temperature data did not plateau at the three-hour mark and was trending towards further separation between HT and RT, which may have allowed for additional sampling points and more powerful leptin data. (ii) Along those same lines, the energy expenditure data also did not plateau and thus, the metabolic profile (RER) data may also have gained statistical power. (iii) In combination with the previous points, a higher core temperature and a clear shift in resources, may have led to significant changes in both uncorrected and PVA leptin concentrations. (iv) Finally, as stated in the methods, all subjects completed an overnight fast prior to entering the laboratory. Therefore, from a reproducibility aspect, it should be highlighted that all subjects were directed to complete an overnight $(10 \mathrm{~h})$ fast prior to the experimental trial in both temperature conditions.

\section{Conclusion}

These results help explain the influence of environmental temperature, independent of exercise, on fasting adipokine concentrations. The addition of heat stress attenuated the leptin reduction, prior to PVA and theoretically maintained an elevated level of satiety. Therefore, fasting in the heat should contribute to increased feeling of satiety. As researchers and practitioners continue to search for new strategies to combat obesity and control hunger, these adipokine results may contribute to mechanistic as well as behavioral aspects of dieting. 


\section{Current Research in Diabetes \& Obesity Journal}

\section{Acknowledgements}

The authors would like to thank the Lab Coordinator Christopher Collins and all the willing and gracious participants for their time and efforts to make this project possible. This publication was funded by grants from the National Institute of General Medical Science (NIGMS) (5P20GM103427 and P20GM109090), a branch of the NIH and its contents are the sole responsibility of the authors.

\section{Declaration of Interest}

The authors declare that there are no conflicts of interest pertaining to this manuscript.

\section{References}

1. James WP (2008) WHO recognition of the global obesity epidemic. Int J Obes (Lond) 32(7): S120-S126.

2. Zhang Y, Proenca R, Maffei M, Barone M, Leopold L, et al. (1994) Positional cloning of the mouse obese gene and its human homologue. Nature 372(6505): 425-432.

3. Heiman ML, Ahima RS, Craft LS, Schoner B, Stephens TW, et al. (1997) Leptin inhibition of the hypothalamic-pituitary-adrenal axis in response to stress. Endocrinology 138(9): 3859-3863.

4. Di Spiezio A, Sandin ES, Dore R, Müller-Fielitz H, Storck SE, et al. (2018) The LepR-mediated leptin transport across brain barriers controls food reward. Mol Metab 8: 13-22.

5. Kubota N, Yano W, Kubota T, Yamauchi T, Itoh S, et al. (2007) Adiponectin stimulates AMP-activated protein kinase in the hypothalamus and increases food intake. Cell Metab 6(1): 55-68.
6. Jeong JH, Lee DK, Liu SM, Chua SC Jr, Schwartz GJ (2018) Activation of temperature-sensitive TRPV1-like receptors in ARC POMC neurons reduces food intake. PLOS Biol 16(4): e2004399.

7. Elmquist JK, Elias CF, Saper CB (1999) From lesions to leptin: Hypothalamic control of food intake and body weight. Neuron 22(2): 221-232.

8. Frederich RC, Löllmann B, Hamann A, Napolitano-Rosen A, Kahn BB, et al. (1995) Expression of ob mRNA and its encoded protein in rodents. impact of nutrition and obesity. J Clin Invest 96(3): 1658-1663.

9. Laursen TL, Zak RB, Shute RJ, Heesch MWS, Dinan NE, et al. (2017) Leptin, adiponectin, and ghrelin responses to endurance exercise in different ambient conditions. Temperature (Austin) 4(2): 166-175.

10. Zak RB, Shute RJ, Heesch MW, La Salle DT, Bubak MP (2017) Impact of hot and cold exposure on human skeletal muscle gene expression. Appl Physiol Nutr Metab 42(3): 319-325.

11. Dill DB, Costill DL (1974) Calculation of percentage changes in volumes of blood, plasma, and red cells in dehydration. J Appl Physiol 37(2): 247-248.

12. Considine RV, Sinha MK, Heiman ML, Kriauciunas A, Stephens TW, et al. (1996) Serum immunoreactive-leptin concentrations in normalweight and obese humans. N Engl J Med 334(5): 292-295.

13. Wilkinson MJ, Manoogian ENC, Zadourian A, Lo H, Fakhouri S, et al (2020) Ten-hour time-restricted eating reduces weight, blood pressure, and atherogenic lipids in patients with metabolic syndrome. Cell Metab 31(1): 92-104.e5.

14. Imbeault P (2007) Environmental influences on adiponectin levels in humans. Appl Physiol Nutr Metab 32(3): 505-511.

15. Fujimatsu D, Kotooka N, Inoue T, Nishiyama M, Node K (2009) Association between high molecular weight adiponectin levels and metabolic parameters. J Atheroscler Thromb 16(5): 553-559.

\begin{tabular}{|l|}
\hline \multicolumn{1}{|c|}{ Your next submission with Juniper Publishers } \\
will reach you the below assets \\
- Quality Editorial service \\
- Swift Peer Review \\
- Reprints availability \\
- E-prints Service \\
- Manuscript Podcast for convenient understanding \\
- Global attainment for your research \\
- Manuscript accessibility in different formats \\
( Pdf, E-pub, Full Text, Audio) \\
- Unceasing customer service \\
Track the below URL for one-step submission \\
https://juniperpublishers.com/online-submission.php \\
\hline
\end{tabular}

